\title{
Designing and evaluation of sodium selenite nanoparticles in vitro to improve selenium absorption in ruminants
}

\author{
Atmir Romero-Pérez • Elizabeth García-García • Araceli Zavaleta-Mancera • \\ J. Efren Ramírez-Bribiesca • Alma Revilla-Vázquez • Luz M. Hernández-Calva • \\ Raquel López-Arellano • Rosy G. Cruz-Monterrosa
}

Accepted: 26 November 2009 / Published online: 18 December 2009

(C) The Author(s) 2009. This article is published with open access at Springerlink.com

\begin{abstract}
Sodium selenite is used to prevent selenium deficiency known as nutritional muscular dystrophy or white muscle disease. In ruminants, selenium supplements are transformed partiality in insoluble form by ruminal microorganisms and its process decrease the selenium absorption in digestive gastrointestinal. However, the objective in this research was focused in encapsulated sodium selenite to be release into of a $\mathrm{pH}$ less than four, similarity to an intestinal environment. It was encapsulated by nanoprecipitation and emulsion-evaporation methods, within polymeric nanoparticles. The effect of these methods, polymer proportion (Eudragit RL and RS) and solvent (ethanol and acetone) on the physicochemical (drug entrapment, polidispersity index (PDI) and z potential) and morphological characteristics (particle morphology and particle size) were evaluated. Particle size from each nanoparticles, formulation ranged from 36.64 to $213.86 \mathrm{~nm}$. Particle size, $\mathrm{z}$ potential and PDI increased $(\mathrm{P} \leq 0.01)$ when nanoprecipitation and ethanol were used. No significant differences $(\mathrm{P}>0.05)$ were observed when different polymeric proportions were used. Selenium entrapment was $26 \%$ when emulsion-evaporation method was used and $78 \%$ with nanoprecipitation. Nanoparticles produced by nanoprecipitation were spherical and had a great variation in particle size; on the other hand, nanoparticles produced by emulsion-evaporation were spherical as well as amorphous and presented a homogeneous nanopartcicle size distribution. The release of selenium from nanoparticles was higher in acid $\mathrm{pH}$ (less than 4), this condition may represent a better availability of the mineral in the small intestine.
\end{abstract}

Keywords Nanoparticles $\cdot$ Sodium selenite $\cdot$ Eudragit $\cdot$ Ruminants

A. Romero-Pérez · A. Zavaleta-Mancera · J. E. Ramírez-Bribiesca $(\bowtie) \cdot$ L. M. Hernández-Calva Colegio de Postgraduados, enlace ganadería, Montecillo Km 36.5 Carr., CP 56230 Texcoco, Mexico e-mail: efrenrb@colpos.mx

E. García-García • A. Revilla-Vázquez • R. López-Arellano

Facultad de Estudios Superiores de Cuautitlán, Universidad Nacional Autónoma de México, Mexico City, México

R. G. Cruz-Monterrosa

Posgrado en Biotecnología, Universidad Autónoma Metropolitana-Iztapalapa, Mexico City, México 


\section{Introduction}

Lack of selenium in ruminants predispose to the white muscle disease (myopathy). In the course of this damage, calcium salts may be deposited among the muscle fibers in certain parts of the bodies of the affected animals. Likewise, inadequate intake of selenium in animals is related to some clinic manifestations like alterations in reproduction, reduction in resistance to diseases, perinatal mortality, retarded growth and wool production decrease (Underwood and Suttle 1999).

Selenium consumed in foods and supplements exists in a number of organic and inorganic forms including selenomethionine (plant and animal sources and supplements), selenocysteine (mainly animal sources), selenate and selenite (mainly supplements) (Rayman 2000). But, selenium deficiency can be prevented by different sources; sodium selenite is a current source using in livestock production.

Efficiency of absorption of selenium differs greatly between ruminants and nonruminants. In ruminants, microbial digestion in the rumen and reticulum precedes digestion in the abomasum and small intestine (NRC 2000). Absorption of selenium is much lower in ruminants than in nonruminants. Absorption of orally administered Se was only $34 \%$ in sheep compared with $85 \%$ in swine (Mahan et al. 1999). Low absorption of selenium in ruminants is believed to result from reduction of dietary selenium to insoluble forms such as elemental selenium or selenides in the rumen environment (Spears 2003). Selenium in ruminant diets is not solely for the animal per se but also for rumen bacteria capable of metabolizing part of it (Serra et al. 1994; Whanger and Weswing 1978). Most of the Se in the ruminal fluids of sheep under supplementation is insoluble, indicating the influence of rumen environment on selenium bioavailability (Serra et al. 1994; Jannes et al. 1989).

In order to avoid this negative side effects polymer nanoparticulate systems are proposed. Up to now, sodium selenite has not been associated with nanoparticles. Consequently, the potentiality of these systems to improve the availability of this microelement was not yet evaluated. The use of Eudragit ${ }^{\circledR}$ RL and Eudragit ${ }^{\circledR}$ RS has been documented for the oral evaluation in rabbits of cyclosporine loaded nanoparticles (Ubrich et al. 2005). Design of sodium selenite nanoparticles for oral administration in ruminants, has not been reported previously. The design and evaluation of controlled release nanoparticles consist in the entrapment of sodium selenite with different methods, solvents and polymer proportions, and further evaluation of the drug entrapment, particle morphology, particle size, z potential and polidispersity index.

\section{Material and methods}

Materials

Sodium selenite was purchased from J.T. Baker ${ }^{\circledR}$, Eudragit ${ }^{\circledR}$ RL and RS were obtained from Helm, Mexico, Pluronic ${ }^{\circledR}$ F68 was from BASF, Germany, Ethanol and Acetone were purchased from J.T. Baker. All other chemicals used were of reagent grade.

Preparation of sodium selenite nanoparticles

Nanoparticles were prepared according to procedures of the, emulsion-evaporation and nanoprecipitation methods. 
Emulsification-evaporation

For this method $200 \mathrm{mg}$ of Eudragit ${ }^{\circledR}$ RL and RS in different proportions (30:70 or 40:60 respectively) were dissolved in $16 \mathrm{~mL}$ of an organic solvent (ethanol or acetone) to obtain the organic solution. $20 \mathrm{mg}$ of sodium selenite were dissolved in $52 \mathrm{~mL}$ of an aqueous solution of Pluronic F68 $(0.5 \%$, w/w). Organic solution was added to the aqueous solution and stirred magnetically during $3 \mathrm{~min}$, and then, stirred with ultraturrax for $3 \mathrm{~min}(9500 \mathrm{rpm})$. Finally, solvent was evaporated by heating the solution $\left(70^{\circ} \mathrm{C}\right)$ during $30 \mathrm{~min}$ and stirring magnetically.

Nanoprecipitation

The organic phase was prepared by dissolving $1000 \mathrm{mg}$ of Eudragit RL and RL (400 mg and $600 \mathrm{mg}$ respectively) in $10 \mathrm{~mL}$ of ethanol by sonication (Transsonic 570/H, ELMA) during $15 \mathrm{~min}$. The organic solution was added into the aqueous phase $(20 \mathrm{~mL})$ containing Pluronic F68 $(0.5 \%$, w/w) and stirred magnetically.

Selenium encapsulation efficiency

The amount of selenium entrapped within the polymeric nanoparticle systems was determined by atomic absorption spectroscopy (AAS). Nanoparticles were recovered by centrifugation at 27,000 rpm/60 min (Beckman-Coulter, Optima L-100 XP). The formed pellets were recovered in $10 \mathrm{~mL}$ of deionized water. Supernatant as well as recovered nanoparticles were digested in nitric acid before injection into the AAS system (SpectrAA, Varian). The encapsulation was referred as the ratio between the selenium found in the nanoparticles and the theoretical quantity of selenium added expressed in percentage.

Particle size, $\mathrm{z}$ potential and PDI

Nanoparticle mean size, polydispersity index, and $\mathrm{z}$ potential were measured using a Zetasizer Nano ZS (Malvern Instruments Ltd., Worcestershire, UK). The mean size and polydispersity of nanoparticles were assessed by photon correlation spectroscopy The PDI values range from 0 to 1 ; a higher value indicates a less homogeneous NP size distribution. The results were all normalized with respect to a polystyrene standard suspension.

Scanning electron microscopy (SEM)

Nanoparticles prepared by emulsion-evaporation

Morphological examination of nanoparticles was performed using a scanning electron microscope (JEOL JSM-35C, Jeol Ltd., Japan). $10 \mu \mathrm{L}$ of nanoparticles were dispersed in $1 \mathrm{ml}$ of deionized water, then drops of the dispersion $(20 \mu \mathrm{L})$ were air-dried over metallic studs, and coated with gold using a gold sputter module in a high vacuum evaporator (Ion Sputter JFC-III00).

\section{Nanoparticles prepared by nanoprecipitation}

After nanoparticle production, nanoparticles were divided into two parts. The first was immediately diluted with distilled water to obtain a dilution 1:100. The second one was centrifuged $(27,000 \mathrm{rpm} / 60 \mathrm{~min})$ and then, the formed pellet was recovered in $10 \mathrm{~mL}$ of 
deionized water. $10 \mu \mathrm{L}$ of each nanoparticle solutions were dispersed in $1 \mathrm{ml}$ of deionized water, and then drops of the dispersions $(20 \mu \mathrm{L})$ were air-dried over metallic studs, and coated with gold using a gold sputter module in a high vacuum evaporator (Ion Sputter JFC-III00). Samples were then observed using a scanning electron microscope (JEOL JSM-6390 Jeol Ltd., Japan).

\section{In vitro selenium release}

In vitro release of selenium from nanoparticles was evaluated in phosphate buffers ( $\mathrm{pH} \mathrm{2,3}$ and 4) and deionized water ( $\mathrm{pH}$ 6). Buffers were prepared according to procedures proposed by Mexican Pharmacopeia (9). Nanoparticle colloids were put into a dialysis membrane (Spectra/ Por $^{\circledR} 3500$ MWCO) and sealed with dialysis membrane closures (Spectra/Por ${ }^{\circledR}$ ), then, the system was put in a flask filled with $900 \mathrm{~mL}$ of deionized water and stirred magnetically during $30 \mathrm{~min}$ in order to eliminate non encapsulated selenium. Dialysis systems containing $5 \mathrm{~mL}$ of purified nanoparticles were prepared and placed in flasks containing $200 \mathrm{~mL}$ of buffer solutions or deionized water, stirred magnetically and maintained at $37^{\circ} \mathrm{C}$. At appropriate intervals $(0,15$, $30,45,60,75,90,105$ and $120 \mathrm{~min}), 20 \mathrm{~mL}$ of the sample were taken and replaced by $20 \mathrm{~mL}$ of each fresh dissolution fluid to maintain a constant volume. The samples were then analyzed by Atomic Absorption Spectrophotometry. The mean of three determinations was used to calculate the drug release from each of the systems.

\section{Statistical analyses}

Statistical analyses for particle size, z potential, PDI and selenium release were carried out with the software package SAS V8 using the GLM procedure (SAS 1999). Means were obtained with the Mean instruction and a multiple comparison among means was done with a Tukey's test. Interaction among solvents and polymer proportions were also evaluated. Means comparison among methods, solvents and polymer proportions was carried out with a Student's t-test. In all cases a value of $\mathrm{P}<0.05$ was considered to be statistically significant.

\section{Results and discussion}

Considering that an important aspect in the preparation of nanoparticles, from both fundamental and technological viewpoints, is the production of a desired particle size with a narrow size

Table 1 Particle size, z potential and PDI of different nanometric systems (mean \pm S.D.)

\begin{tabular}{llll}
\hline System & Particle size $(\mathrm{nm})$ & Z potential Z (mV) & PDI \\
\hline E. E. Acetone 30:70 & $44.8 \pm 0.55 \mathrm{~b}$ & $26.7 \pm 1.1 \mathrm{~b}$ & $0.379 \pm 0.004 \mathrm{~b}$ \\
E. E. Acetone 40:60 & $42.6 \pm 0.22 \mathrm{c}$ & $25.9 \pm 2.4 \mathrm{cb}$ & $0.374 \pm 0.014 \mathrm{~b}$ \\
E. E. Ethanol 30:70 & $34.6 \pm 0.05 \mathrm{e}$ & $19.1 \pm 1.0 \mathrm{~d}$ & $0.233 \pm 0.004 \mathrm{~d}$ \\
E. E. Ethanol 40:60 & $38.9 \pm 0.61 \mathrm{~d}$ & $22.6 \pm 1.0 \mathrm{~cd}$ & $0.343 \pm 0.003 \mathrm{c}$ \\
N. P. Ethanol 40:60 & $213.8 \pm 1.38 \mathrm{a}$ & $31.8 \pm 0.7 \mathrm{a}$ & $0.494 \pm 0.005 \mathrm{a}$ \\
\hline
\end{tabular}

Means with different letters within a column are significantly different $(\mathrm{P}<0.05)$

E.E. $=$ Emulsion-Evaporation

N.P. $=$ Nanoprecipitation

$30: 70=30 \%$ Eudragit RL and 70\% de Eudragit RS

40:60 $=40 \%$ Eudragit RL and $60 \%$ de Eudragit RS 
Table 2 Particle size, z potential and PDI of nanoparticles prepared by different methods (mean \pm S.D.)

\begin{tabular}{llll}
\hline Method & Particle size $(\mathrm{nm})$ & Z potential Z $(\mathrm{mV})$ & PDI \\
\hline Emulsion-Evaporation & $40.2 \pm 4.05 \mathrm{a}$ & $23.6 \pm 3.3 \mathrm{~b}$ & $0.332 \pm 0.062 \mathrm{~b}$ \\
Nanoprecipitation & $213.8 \pm 1.37 \mathrm{~b}$ & $31.8 \pm 0.7 \mathrm{a}$ & $0.494 \pm 0.004 \mathrm{a}$ \\
\hline
\end{tabular}

Means with different letters within a column are significantly different $(\mathrm{P}<0.05)$

distribution and a good stability (Galindo et al. 2004), all methods were compared by analyzing the physicochemical variables that could affect these nanoparticle characteristics.

The mean particle size, $\mathrm{z}$ potential and PDI of different nanometric systems are presented in Table 1. All nanometric systems presented significant differences for the evaluated variables $(\mathrm{P}<0.05)$. The system N. P. Ethanol 40:60 showed the major values for all variables, it presented a mean particle size of $213.8 \mathrm{~nm}$ and a $\mathrm{z}$ potential value of $31.8 \mathrm{mV}$. Recommend values of $\mathrm{z}$ potential for colloid suspension must have values superior to $\pm 30 \mathrm{mV}$ (12). The magnitude of the zeta potential gives an indication of the potential stability of the colloidal system. If all the particles in suspension have a large negative or positive zeta potential then they will tend to repel each other and there will be no tendency for the particles to come together. However, if the particles have low zeta potential values then there will be no force to prevent the particles coming together and flocculating. The highest PDI indicates that nanoparticles generated by this system had the lowest homogeneity in size distribution.

The lowest values for evaluated variables were obtained in E. E. Ethanol 30:70 system, it showed a mean particle size of $34.6 \mathrm{~nm}$ and a PDI of 0.233 that is directly related to the best particle size distribution of all evaluated systems, however, this system is not stable according to the minimum recommended value of $\mathrm{z}$ potential proposed by Malvern Instruments $(30 \mathrm{mV})$.

All results differed significantly $(\mathrm{P}<0.05)$ between the two production methods (Table 2$)$. Nanoparticles produced by nanoprecipitation were $431 \%$ bigger than nanopartiles produced by emulsion-evaporation. Z potential and PDI increased 34.9 and $48.7 \%$ when nanoprecipitation was used. Nanoprecipitation showed a $\mathrm{z}$ potential value superior to the minimum recommended for stable colloidal suspensions $(30 \mathrm{mV})$, nevertheless, it showed a high value for PDI, which suggest that mean particle size presented a great variation.

Fig. 1 Scanning electron micrographs of microparticles and nanoparticles prepared by (a) emulsion-evaporation and (b) nanoprecipitation

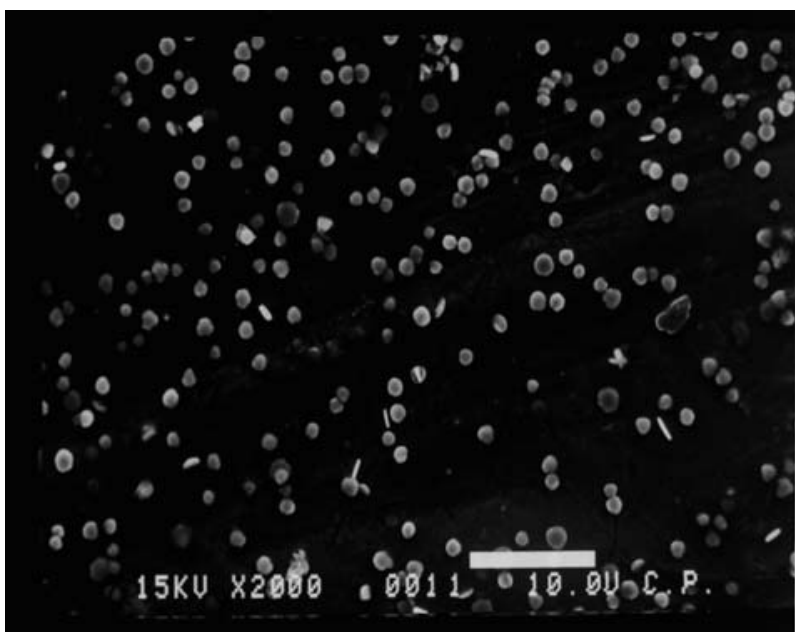


Table 3 Particle size, z potential and PDI of nanoparticles prepared with different solvents (mean \pm S.D.)

\begin{tabular}{llll}
\hline Solvent & Particle size $(\mathrm{nm})$ & Z potential Z $(\mathrm{mV})$ & PDI \\
\hline Ethanol & $43.4 \pm 1.23 \mathrm{a}$ & $26.3 \pm 1.7 \mathrm{a}$ & $0.376 \pm 0.009 \mathrm{a}$ \\
Acetone & $36.8 \pm 2.39 \mathrm{~b}$ & $20.9 \pm 2.1 \mathrm{~b}$ & $0.288 \pm 0.060 \mathrm{~b}$ \\
\hline
\end{tabular}

Means with different letters within a column are significantly different $(\mathrm{P}<0.05)$

Nanoparticles produced by nanoprecipitation were spherical, while nanoparticles produced by emulsion-evaporation were spherical as well as irregular (Fig. 1). Even zetasizer showed a mean particle size for emulsion-evaporation method less than $45 \mathrm{~nm}$, nanoparticles were not observed in SEM, probably due to nanoparticles were not purified before observation and excess of polymer could interfere in the characterization process (Raula et al. 2004). In the other hand, nanoparticles produced by nanoprecipitation were successfully characterized. In this case excess of polymer was eliminated by centrifugation $(27,000 \mathrm{rpm} / 60 \mathrm{~min}$ ) before characterization and did not interfere in SEM examination. Other works produced tracolimus nanoparticles using the polymer poly (lactic-co-glycolic acid) and the emulsion evaporation method. The encapsulation of tracolimus resulted in spherical particles with the diameter varying between 30 and $60 \mu \mathrm{m}$. Microparticles were successfully characterized, however, when microparticles were prepared under reduced pressure at room temperature, the evaporation of the inner aqueous phase resulted in a sponge-like structure. Lowering the temperature with an ice bath led to distinctly less porous particles with a relatively smooth surface (Lamprecht et al. 2004).

Particle size, $\mathrm{z}$ potential and PDI differed significantly $(\mathrm{P}<0.05)$ when two different solvents were used in nanoparticle preparation (Table 3). When ethanol was used nanoparticle size grater $18 \%$, z potential $25 \%$ and PDI $30 \%$. Even if use of ethanol guarantees a better stability of the system, it must be remembered that a higher value of PDI is related with a less homogeneous particle size distribution.

The formation of spherical nanoparticles and their morphology can be influenced by proper experimental conditions. The solubility of the polymer in the solvent and the volatility of the solvent are probably the most important factors that influence on the particle formation. A concept of solvent quality for a polymer is noteworthy. As the solubility of the polymer increases, the solvent quality for the polymer improves, and vice versa. The solvent medium is, therefore, good or poor for the polymer, respectively. In a good solvent, polymer chains are expanded, whereas they shrink and eventually phase separates when the solvent quality worsens. In the good solvent, the polymer-solvent interactions dominate, whereas this is replaced by the interactions between polymer chains in the poor solvent (Raula et al. 2004). Polymer Eudragit RL 100 y RS 100 in this work showed a better solubility in acetone, this

Table 4 Particle size, z potential and PDI of nanoparticles prepared with different polymers proportions (mean \pm S.D.)

\begin{tabular}{llll}
\hline Proportion & Particle size $(\mathrm{nm})$ & Z potential Z $(\mathrm{mV})$ & PDI \\
\hline $30: 70$ & $39.7 \pm 5.58 \mathrm{a}$ & $22.9 \pm 4.2 \mathrm{a}$ & $0.306 \pm 0.080 \mathrm{a}$ \\
$40: 60$ & $40.8 \pm 2.07 \mathrm{a}$ & $24.3 \pm 2.4 \mathrm{a}$ & $0.359 \pm 0.019 \mathrm{a}$ \\
\hline
\end{tabular}

Means with different letters within a column are significantly different $(\mathrm{P}<0.05)$

$30: 70=30 \%$ Eudragit RL y $70 \%$ de Eudragit RS

$40: 60=40 \%$ Eudragit RL y $60 \%$ de Eudragit RS 
Table 5 Particle size, z potential and PDI correlations

\begin{tabular}{llll}
\hline Item & Particle size $(\mathrm{nm})$ & $\mathrm{Z}$ potential $\mathrm{Z}(\mathrm{mV})$ & PDI \\
\hline Particle size $(\mathrm{nm})$ & 1 & 0.912 & 0.930 \\
Z potential Z $(\mathrm{mV})$ & 0.912 & 1 & 0.881 \\
PDI & 0.930 & 0.881 & 1 \\
\hline
\end{tabular}

Correlation is significant at the 0.01 level (2-tailed)

difference in solubility of the polymers in solvents, may explain differences observed in evaluates variables.

None of the results did differ significantly $(\mathrm{P}>0.05)$ between the two polymer proportions $(\mathrm{P}>0.05$, Table 4$)$, probably due to differences in polymeric proportions were not strongly marked. Further works must evaluate polymeric proportions strongly marked and Eudragit RL and RS polymers individually. Solvent proportion interaction was evaluated; all variables presented a significant interaction: mean particle size $(\mathrm{P}<0.0001)$, z potential $(\mathrm{P}<0.0396)$ and PDI $(\mathrm{P}<0.0001)$.

Table 5 displays correlations between evaluated variables. Mean particle size is direct correlated to $\mathrm{z}$ potential $\left(\mathrm{r}^{2}=0.912, \mathrm{P}<0.01\right)$. Bigger nanoparticles are more stables, because higher $\mathrm{z}$ potential values are related to a more stables colloidal systems. Particle size also shows a good correlation with PDI $\left(\mathrm{r}^{2}=0.930 ; \mathrm{P}<0.01\right)$. Bigger particles are more variable in particle size distribution, due to high values of PDI correspond to a less homogeneous particle size. $\mathrm{Z}$ potential and PDI have a positive correlation $\left(\mathrm{r}^{2}=0.881 ; \mathrm{P}<0.01\right)$; when $\mathrm{Z}$ potential and PDI increases, nanoparticles becomes more stables but homogeneity in particle size distribution decreases. It is necessary to have a balance between these variables in order to achieve stable particles with a good distribution of the particle size. Data also were analyzed for quadratic regression, obtaining this formula. $\mathrm{Y}=64.604-264.31 \mathrm{x}-$ 504.584 $\mathrm{x}^{2}\left(\mathrm{R}^{2}=0.921, \mathrm{P}<0.001\right)$ where: $\mathrm{Y}=$ particle size and $\mathrm{x}=\mathrm{PDI}$.

Selenium release from nanoparticles in different $\mathrm{pH}$ and time are presented in Fig. 2. The maximum selenium release is obtained before minute 45 in all cases. Selenium release presented significantly differences $(\mathrm{P}<0.05)$ for different times in all $\mathrm{pH}$ values. Lower values than $\mathrm{pH} 4$, increased the selenium release in $62 \%$ compared with $\mathrm{pH} 6$. The results may have a positive impact on animal production. The rumen $\mathrm{pH}$ vary from 5.5 to 6.5 , out of this values, animals may have problems of acidosis or alkalosis. Essentially, no absorption of selenium occurred in the rumen and abomasum, and the greatest absorption of selenium

Fig. 2 Released selenium from sodium selenite nanoparticles $(\mu \mathrm{g} / \mathrm{mL})$ in different $\mathrm{pH}$ and times

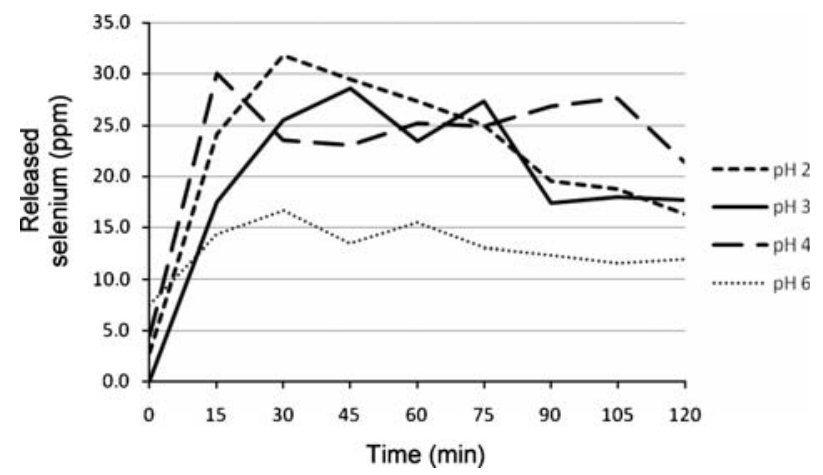


occurred in the small intestine and the cecum of sheep (NRC 1983). Low absorption of selenium in ruminants is believed to result from reduction of dietary selenium to insoluble forms such as elemental selenium or selenides in the rumen environment. This selenium is not available for the animal (Spears 2003). The abomasum and duodenum $\mathrm{pH}$ is less to 4; under this condition nanoparticles present the highest release. Nanoparticles may represent an advantage to increase bioavailability of the mineral, because, it dose a low concentration in $\mathrm{pH}$ 6, this benefit to rumen microorganisms which are capable of metabolizing part of it and the mayor release of selenium occurs in acid condition, this may represent a better availability of the mineral in the small intestine. This in vitro study shows positive results in order to evaluate sodium selenite nanoparticles in an in vivo study.

\section{Conclusion}

This study shows that the encapsulation of sodium selenite in nanoparticles by the emulsionevaporation and nanoprecipitation methods when using Eudragit RL and RS is feasible. Nanoprecipitation generated spherical nanoparticles with a great variation in particle size distribution while nanoparticles prepared by emulsion-evaporation presented spherical as well as amorphous nanoparticles, and a great homogeneity of particle size. Nanoparticles prepared by nanoprecipitation were more stables since $\mathrm{z}$ potential increased $34.9 \%$. When ethanol was used, particle size increased $18 \%$ and particles were more stables but particle size distribution was less homogeneous. Different polymer proportions evaluated were not different. All evaluated variables showed a good correlation. A balance among evaluated variables must be achieved to produce nanoparticles with a desired particle size, stability and particle size distribution.

Acknowledgments This work was supported by line 16: Technology Innovation and Nanothecnology. Colegio de Postgraduados. México.

Open Access This article is distributed under the terms of the Creative Commons Attribution Noncommercial License which permits any noncommercial use, distribution, and reproduction in any medium, provided the original author(s) and source are credited.

\section{References}

Galindo SR, Allemann E, Fessi H, Doelker E (2004) Physicochemical parameters associated with nanoparticle formation in the salting-out, emulsification-diffusion, and nanoprecipitation methods. Pharmac Res 21:1428-1439.

Jannes BJ, Deagen JT, Beilstein MA, Whanger PD (1989) Comparative metabolism of organic and inorganic selenium by sheep. J Agric Food Chem 37:1358-1363.

Lamprecht A, Yamamoto H, Takeuchi H, Kawashima Y (2004) pH-sensitive microsphere delivery increases oral bioavailability of calcitonin. J Control Rel 98:1-9.

Mahan DC, Cline TR, Richert B (1999) Effects of dietary levels of selenium-enriched yeast and sodium selenite as selenium sources fed to growing-finishing pigs on performance, tissue selenium, serum glutathione peroxidase activity, carcass characteristics, and loin quality. J Anim Sci 77: 2172-2179.

NRC (2000) Nutrient Requirement for Beef Cattle (8th) Ed. National Academy Press. Washington, DC.

NRC (1983) Selenium in Nutrition Ed. National Academy Press. Washington, DC.

Raula J, Eerikäinen H, Kauppinen EI (2004) Influence of the solvent composition on the aerosol synthesis of pharmaceutical polymer nanoparticles. Inten J Pharm 284:13-21

Rayman MP (2000) The importance of selenium to human health. Lancet 356:233-241. 
SAS/STAT (1999) User's Guide, Version 8, SAS Inst., Inc., Cary, North Carolina.

Serra AB, Nakamura K, Matsui T, Harumoto H. Fujihara T (1994) Inorganic selenium for sheep I. Selenium balance and selenium levels in the different ruminal fluid fractions. Asian J Anim Sci 7:83-89.

Spears JW (2003) Trace mineral bioavailability in ruminants. J Nutr 133:1506S-1509S.

Ubrich N, Scmidt C. Bodmeirer R, Hoffman M, Maincent P (2005) Oral evaluation in rabbits of cyclosporinloaded Eudragit RS or RL nanoparticles. Int J Pharmac 288:169-175.

Underwood EJ, Suttle NF (1999) The mineral nutrition of livestock, 3rd ed, CABI Publishing. NY, USA.

Whanger PD, Weswing PH (1978) Oldfield JE. Selenium, sulfur and nitrogen levels in ovine rumen microorganisms. J Anim Sci 46:515-519. 